\title{
On the long-term aging of S-phase in aluminum alloy 2618A
}

Christian Rockenhäuser ${ }^{1}$ (D), Christian Rowolt ${ }^{2}$ (D), Benjamin Milkereit ${ }^{2,3}$ (D), Reza Darvishi Kamachali ${ }^{1}$, Olaf Kessler ${ }^{2,3}$ (1), and Birgit Skrotzki ${ }^{1, *}$ (1)

${ }^{1}$ Bundesanstalt für Materialforschung und -prüfung (BAM), Experimental and Model Based Mechanical Behavior of Materials, Unter den Eichen 87, 12205 Berlin, Germany

${ }^{2}$ Universität Rostock, Lehrstuhl für Werkstofftechnik, Justus-von-Liebig-Weg 2, 18059 Rostock, Germany

${ }^{3}$ Competence Centre ${ }^{\circ}$ CALOR, Department Life, Light \& Matter, University of Rostock, Albert-Einstein-Str. 25, 18059 Rostock, Germany

Received: 21 August 2020

Accepted: 24 December 2020

Published online:

11 January 2021

(C) The Author(s) 2021

\begin{abstract}
The aluminum alloy 2618A is applied for engine components such as radial compressor wheels which operate for long time at elevated temperatures. This results in coarsening of the hardening precipitates and degradation in mechanical properties during the long-term operation, which is not taken into account in the current lifetime prediction models due to the lack of quantitative microstructural and mechanical data. To address this issue, a quantitative investigation on the evolution of precipitates during long-term aging at $190{ }^{\circ} \mathrm{C}$ for up to $25,000 \mathrm{~h}$ was conducted. Detailed transmission electron microscopy (TEM) was combined with Brinell hardness measurements and thorough differential scanning calorimetry (DSC) experiments. The results show that GPB zones and S-phase $\mathrm{Al}_{2} \mathrm{CuMg}$ grow up to $<1,000 \mathrm{~h}$ during which the GPB zones dissolve and S-phase precipitates form. For longer aging times, only S-phase precipitates coarsen, which can be well described using the Lifshitz-Slyozov-Wagner theory of ripening. A thorough understanding of the underlying microstructural processes is a prerequisite to enable the integration of aging behavior into the established lifetime models for components manufactured from alloy 2618A.
\end{abstract}

\section{Introduction}

The Al-Cu-Mg alloy EN AW 2618A (EN AW $\mathrm{AlCu} 2 \mathrm{Mg} 1.5 \mathrm{Ni}$ ) is used for applications subjected to long-term service at elevated temperatures in the aerospace and transportation industry due to its favorable material properties (e.g., slow long-term degradation) [1]. It contains $\mathrm{Fe}$ and $\mathrm{Ni}$ in the form of intermetallic compounds of $\mu \mathrm{m}$ size, which retain microstructural stability and provide dispersion

Handling Editor: David Balloy.

Address correspondence to E-mail: Birgit.Skrotzki@bam.de 
hardening at elevated temperatures [2-5]. The size and distribution of the nm-sized secondary S-phase and its precursors are the main factors influencing the material strength. These precipitates are formed within the supersaturated solid solution (SSSS) during aging [6-10]. The equilibrium S-phase has the composition $\mathrm{Al}_{2} \mathrm{CuMg}$, and its crystal structure is orthorhombic [11, 12]. The first decomposition sequence proposed was [13, 14]:

$$
\text { SSSS } \rightarrow \text { GPB zone } \rightarrow \mathrm{S}^{\prime \prime}+\mathrm{S}^{\prime} \rightarrow \mathrm{S}^{\prime}+\mathrm{S} \rightarrow \mathrm{S}
$$

The Guinier-Preston-Bagaryatski (GPB) zones, named by Silcock [13], are rod-shaped precipitates of 1-2 $\mathrm{nm}$ in diameter. $\mathrm{S}^{\prime \prime}$ and $\mathrm{S}^{\prime}$ were reported to be metastable variants of the S-phase. It was later suggested by Ringer et al. that the GPB zones are preceded by $\mathrm{Cu}-\mathrm{Mg}$ co-clusters [15-17]. In general, the decomposition sequence of the rod-shaped hardening phases during isothermal aging remains under debate $[18,19]$. In this work, the different variants of the S-phase are not distinguished and collectively referred to as S-phase in the following.

Components made of 2618A such as radial compressor wheels need to operate at elevated temperatures, close to the aging temperature for establishing the T61 condition, for very long periods of time. This results in coarsening of the hardening precipitates. To describe the influence of the $\mathrm{S}-\mathrm{Al}_{2} \mathrm{CuMg}$ phase coarsening on material properties in a more quantitative manner, it is necessary to investigate the evolution of the precipitate size during aging. This, in turn, enables the integration of the aging behavior into the established lifetime models for components manufactured from alloy 2618A.

The first quantitative description of the coarsening of spherical precipitates (Ostwald ripening) was proposed by Lifshitz and Slyozov [20] and Wagner [21]:

$r^{3}-r_{0}^{3}=k\left(t-t_{0}\right)$

where $r$ is the mean radius (equivalent to $r_{\mathrm{a}}$ for cylindrical precipitates in the following sections), $r_{0}$ is the initial mean radius corresponding to the initial time $t_{0}, k$ is a material-dependent constant and $t$ is the coarsening time. However, the derived equation is only valid, if the following conditions are met: (i) The mass transport needs to be isotropic, (ii) the precipitates exhibit a statistical size distribution, (iii) there is no local strain of the lattice during coarsening, and (iv) the volume fraction of the secondary phase is small. Oriented cylindrical particles, as investigated in this work, require a modification of eqn. (1). For this case, Speich and Oriani [22] derived the same power law as given above; however, the constant $k$ was modified by the aspect ratio $\beta$ of the precipitates. This means an additional condition for Ostwald ripening to occur is set: (v) The aspect ratio of the particles is constant during the coarsening process. A study by Monzen et al. confirmed this for $\alpha$-Fe particles in a $\mathrm{Cu}$ matrix [23].

The coarsening process is not only associated with an increasing radius, but also with a rising particle distance. Thus, the mechanical strength decreases according to the well-known Orowan equation [24]:

$\Delta \tau=\frac{\mathrm{Gb}}{2 \pi \sqrt{1-v}} * \frac{1}{\lambda} * \ln \frac{\pi 2 r}{4 b}$

Here, $\Delta \tau$ is the increment in critical resolved shear stress due to particle strengthening, $v$ the Poisson's ratio, $G$ the shear modulus, $b$ the Burgers vector of gliding dislocations, $\lambda$ the effective interparticle spacing, and $r$ the precipitate radius. $\lambda$ varies with shape, orientation and distribution of the particles, i.e., mean particle distance. The parameters $r$ and $\lambda$ can be obtained using eqn. (1) and certain mean-field and geometrical assumptions.

The microstructure evolution of peak-aged samples of alloy 2618A during thermal exposure was studied by different groups. Ceschini et al. reported that exposure at temperatures $\geq 200{ }^{\circ} \mathrm{C}$ results in a significant decrease in sample hardness [25]. Their microstructural investigations show that the hardness decrease over time coincides with a coarsening of the S- $\mathrm{Al}_{2} \mathrm{CuMg}$ precipitates without giving quantitative parameters for the S-phase aging process. The influence of creep stress on the microstructural changes in alloy 2618A was studied qualitatively by Nový et al. [26, 27]. They found that coarsening of the S-phase occurs and precipitate-free zones along the grain boundaries form after aging at a temperature of $270{ }^{\circ} \mathrm{C}$ and different tensile creep loads. It is stated that these zones have a detrimental influence on the mechanical properties of the alloy.

Based on this background, Rockenhäuser et al. presented a study to contribute to a more quantitative understanding of the S-phase coarsening process in alloy 2618A, especially regarding lower temperatures $\left(\leq 200{ }^{\circ} \mathrm{C}\right)$ which are more relevant for operating 
conditions in engine applications [28]. The study provided a quantitative coarsening model for samples undergoing creep loads. However, it was not possible, to transfer this ripening model to ripening without external stresses. The reasons for this were the difficulty to discriminate between small S-phase precipitates and their predecessors, the GPB zones, and to determine whether GPB zones are still present in the material. It was shown in various studies on GPB zones and S-phase precipitates that differential scanning calorimetry (DSC) is a viable method to investigate the presence of the two different secondary phases [29].

The aim of the present study is to develop a quantitative investigation of isothermal (stress free) aging by complementing transmission electron microscopy (TEM) with thorough differential scanning calorimetry (DSC) measurements and hardness tests to allow a more in-depth understanding of the S-phase aging process. In addition, very long aging times (up to $25,000 \mathrm{~h}$ ) were considered to ensure the long-term validity of the aging model relevant to the real-world operation conditions. A quantitative description of the evolution of precipitates provides the basis for precise lifetime prediction concepts for alloy 2618A.

\section{Material and experimental methods}

The starting material for all fabricated and investigated samples is forged circular blanks (diameter ca. $195 \mathrm{~mm}$, thickness ca. $130 \mathrm{~mm}$ ) made from alloy 2618A in T61 condition according to DIN EN 515 [30] with a chemical composition shown in Table 1 [31]. The T61 condition includes a solution heat treatment, quenching and aging heat treatment which leads to a slightly underaged condition. In this case, the solution heat treatment was carried out at $530{ }^{\circ} \mathrm{C}$ for $8 \mathrm{~h}$, followed by quenching in boiling water and aging at $195{ }^{\circ} \mathrm{C}$ for $28 \mathrm{~h}$. The rather long solution heat treatment time of $8 \mathrm{~h}$ was chosen in order to reliably dissolve any coarse precipitates that may be present in the relatively large cross section of the forged disks after forming and to maximize the content of alloying elements in solid solution.

Square bulk samples (30 $\mathrm{mm} \times 30 \mathrm{~mm})$ with a thickness of $4 \mathrm{~mm}$ were cut by wire electrical discharge machining from the blank for the aging treatment. The plates were aged at $190{ }^{\circ} \mathrm{C}$ for $0 \mathrm{~h}$,
$250 \mathrm{~h}, 1,000 \mathrm{~h}, 2,500 \mathrm{~h}, 5,000 \mathrm{~h}, 8,760 \mathrm{~h}$ (1 year), and $25,000 \mathrm{~h}$ ( $\sim 3$ year). This temperature corresponds approximately to the operation conditions of engine components. The temperature of the furnace was continuously recorded using two thermocouples close to the blanks. The accuracy of the solution heat treatment was $\pm 2 \mathrm{~K}$ and of the long-term aging treatment significantly better than $\pm 2^{\circ} \mathrm{K}$ on average, with a total of less than ten very short-term deviations of up to $\pm 4^{\circ} \mathrm{K}$. The blanks were continuously aged with one interruption after approx. 8,950 h.

In order to understand the phase behavior of the material, equilibrium thermodynamic calculations of the alloy have been conducted. These calculations are used as a basis for the precipitation analysis.

The Brinell hardness, HBW 2.5/62.5, was determined from the polished square bulk samples using an Emco Test M4C 025 G3 hardness tester according to DIN EN 6506-1 (five measurements, distances between sample edge and indentations $\geq 3 \mathrm{~mm}$, and between indentations $\geq 3.5 \mathrm{~mm}$ ) [32]. The measurement uncertainty is $\leq 2.5 \mathrm{HBW}$ for all samples.

Subsequently, the samples were prepared for transmission electron microscopy. Platelets/disks were mechanically cut from the aged samples with a thickness of about $500 \mu \mathrm{m}$. Then, the samples were carefully ground using increasingly fine abrasive papers (down to grid size P1000) to a final thickness of about $130 \mu \mathrm{m}$. The final step of mechanical preparation was punching uniform disks with a diameter of $3 \mathrm{~mm}$. To achieve electron transparency, the disks were electropolished by twin-jet polishing in a Tenupol-3 electropolishing device (Struers) at a voltage of $12 \mathrm{~V}$. An electrolyte with two parts methanol (pure) and one part nitric acid (65\%) cooled to $-20{ }^{\circ} \mathrm{C}$ was used. A previous study by Ünlü readily provided the acceptable parameters for electropolishing [33].

The electron microscopical investigations were performed in a JEM - 2200FS TEM/scanning TEM transmission electron microscope with a field-emission gun operating at $200 \mathrm{kV}$. At least ten images were taken at different places of each sample. All images were acquired at a magnification of $60.000 x$ with an edge length of $317 \mathrm{~nm}$.

In addition, samples were prepared for differential scanning calorimetry from the investigated square bulk samples. Flat cylinders (diameter $6.4 \mathrm{~mm}$, height $1 \mathrm{~mm}$, weight $\approx 87 \mathrm{mg}$ ) were cut by wire electrical discharge machining from the plates and 
Table 1 Actual composition of alloy $2618 \mathrm{~A}$

\begin{tabular}{llllllllll}
\hline Element & $\mathrm{Cu}$ & $\mathrm{Mg}$ & $\mathrm{Fe}$ & $\mathrm{Ni}$ & $\mathrm{Si}$ & $\mathrm{Mn}$ & $\mathrm{Zn}$ & $\mathrm{Ti}$ & $\mathrm{Al}$ \\
\hline wt. \% & 2.5 & 1.6 & 1.1 & 1.1 & 0.24 & $<0.1$ & $<0.1$ & 0.06 & Balance \\
\hline
\end{tabular}

then further prepared by grinding for DSC measurements. Mechanical preparation was done carefully to avoid any further heat input. In order to investigate the stability of phases formed during aging, DSC heating experiments were performed. Therefore, a PerkinElmer Pyris Diamond DSC was used. A broad temperature range was set from $-50{ }^{\circ} \mathrm{C}$ up to $560{ }^{\circ} \mathrm{C}$, while a heating rate of $1 \mathrm{~K} \mathrm{~s}^{-1}$ was applied intending to detect all potential dissolution and precipitation reactions. Pure aluminum (99.9995\%) with the same dimensions as the samples was used as reference material. The evaluation of DSC heating experiments was done according to the method proposed by Kemsies et al. [34]. At least three individual samples for each initial condition were investigated. All DSC results shown in this work represent the average curve for each initial condition.

\section{Results}

\section{Brinell hardness}

The presence of material degradation due to coarsening was documented by measuring the Brinell hardness. The results are given in Table 2 and are shown in Fig. 1. As expected, material degradation clearly took place. An initially fast decrease from $140 \mathrm{HBW}$ (T61 condition) to $116 \mathrm{HBW}$ after $250 \mathrm{~h}$ can be observed. The hardness decrease then slows down in the following, and a final hardness of $99 \mathrm{HBW}$ is measured after 25,000 h of aging.

\section{Equilibrium thermodynamic calculations}

Quasi-ternary phase diagrams have been calculated using Thermo-Calc TCAL07 database (Fig. 2a and b). The phase diagrams at $530{ }^{\circ} \mathrm{C}$ and $190{ }^{\circ} \mathrm{C}$ show that the S-phase is rather stable at lower temperatures, but higher amounts of $\mathrm{Cu}$ and/or $\mathrm{Mg}$ can stabilize the S-phase at higher temperatures. The equilibrium phase fractions between $100{ }^{\circ} \mathrm{C}$ and $600{ }^{\circ} \mathrm{C}$ are presented in Fig. 2c.

The commercial alloy composition (Table 1) results in a complex sequence of phase transformations.
Here, however, we limit our calculations to major phases including the $\mathrm{Mg}_{2} \mathrm{Si}, \mathrm{Al}_{9} \mathrm{M}_{2}$ (i.e., $\mathrm{Al}_{9} \mathrm{FeNi}$ ), $\mathrm{Al}_{9} \mathrm{M}_{3}$ (i.e., $\mathrm{Al}_{9} \mathrm{Mn}_{2} \mathrm{Zn}$ ), $\mathrm{Al}_{9} \mathrm{M}_{4}$ (i.e., $\mathrm{Al}_{9} \mathrm{Fe}_{2} \mathrm{Si}_{2}$ ) and S-phase precipitates in the Al-rich FCC matrix. It is found that the $\mathrm{Mg}_{2} \mathrm{Si}$ and $\mathrm{Al}_{9} \mathrm{M}_{4}$ primary phases can be rather stable over the whole range of temperature. For temperatures above $400{ }^{\circ} \mathrm{C}$, the stability of the S-phase rapidly drops. At the solution heat treatment temperature $530{ }^{\circ} \mathrm{C}$, these two phases exist, while the strengthening S-phase dissolves. Table 3 lists the equilibrium phase fractions calculated for the current alloy composition. At the aging temperature $190{ }^{\circ} \mathrm{C}$, the S-phase can reach its equilibrium maximum volume fraction of about 4.3 vol. $\%$.

\section{DSC measurements}

DSC measurements were performed to determine the presence of GPB zones in the material. It was expected that the underaged T61 condition contains both GPB zones and S-phase and that the amount of GPB zones then decreases during the aging process. Figure 3 shows the results of the DSC heating measurements after different aging durations. The dotted, horizontal line indicates the zero level. The DSC results are given in the unit excess specific heat, meaning that deviations above the zero level indicate the dominance of endothermic dissolution reactions, while deviations below the zero level indicate the dominance of exothermic precipitation reactions.

First endothermic reactions start at $\sim 220{ }^{\circ} \mathrm{C}$ for all investigated samples. In case of the T61 state (red curve), the earliest beginning of an endothermic dissolution reaction (peak A) is recognizable. This endothermic reaction exhibits a maximum at $\sim 280^{\circ} \mathrm{C}$. This is very likely related to the dissolved fraction of GPB zones that transforms into the S-phase, also evidenced by the dissolution (peak A) directly followed by exothermic precipitation (peak b). This exothermic reaction starts at $\sim 300{ }^{\circ} \mathrm{C}$ and reaches its minimum at $\sim 330{ }^{\circ} \mathrm{C}$. One should be aware that the two types of reactions are very likely to overlap. For temperatures higher than about $400{ }^{\circ} \mathrm{C}$, the DSC curves of all initial aging states are very similar and show an endothermal dissolution of 
Table 2 Sample designation, aging temperature, $T$, aging time, $t$, resulting median particle radii, $r_{\mathrm{m}}$, geometric standard deviation, $\sigma_{\text {geo, }}$ Brinell hardness, HBW, and calculated average radii, $r_{\mathrm{a}}$.

\begin{tabular}{llllcll}
\hline Sample designation & $\mathrm{T}\left({ }^{\circ} \mathrm{C}\right)$ & $\mathrm{t}(\mathrm{h})$ & $\mathrm{r}_{\mathrm{m}}(\mathrm{nm})$ & $\sigma_{\text {geo }}$ & HBW 2.5/62.5 & $\mathrm{r}_{\mathrm{a}}(\mathrm{nm})$ \\
\hline Sample 1 & None & 0 & $1.56 \pm 0.04$ & $0.52 \pm 0.01$ & 140 & 1.79 \\
Sample 2 & 190 & 24 & - & - & 133 & - \\
Sample 3 & 190 & 100 & - & - & 122 & - \\
Sample 4 & 190 & 250 & $2.03 \pm 0.08$ & $0.70 \pm 0.03$ & 116 & 2.61 \\
Sample 5 & 190 & 1,000 & $3.05 \pm 0.30$ & $0.91 \pm 0.06$ & 113 & 4.65 \\
Sample 6 & 190 & 2,500 & $3.63 \pm 0.27$ & $0.80 \pm 0.05$ & 110 & 5.00 \\
Sample 7 & 190 & 5,000 & $4.04 \pm 0.38$ & $0.78 \pm 0.07$ & 109 & 5.50 \\
Sample 8 & 190 & 8,760 & $5.64 \pm 0.20$ & $0.41 \pm 0.03$ & 106 & 6.14 \\
Sample 9 & 190 & 25,000 & $7.36 \pm 0.21$ & $0.42 \pm 0.02$ & 99 & 8.03
\end{tabular}

Table 3 The equilibrium phase fractions (vol.\%) obtained using Thermo-Calc, TCAL07 database

\begin{tabular}{lllll}
\hline $\mathrm{T}\left({ }^{\circ} \mathrm{C}\right)$ & S-phase & $\mathrm{Mg}_{2} \mathrm{Si}$ & $\mathrm{Al}_{9} \mathrm{M}_{\mathrm{x}}$ & $\mathrm{FCC}$ (matrix) \\
\hline $530{ }^{\circ} \mathrm{C}$ & 0 & 0.2 & 5.7 & 94.1 \\
$190{ }^{\circ} \mathrm{C}$ & 4.3 & 0.4 & 6.0 & 89.3 \\
\hline
\end{tabular}

peak area with increasing initial aging times at $190{ }^{\circ} \mathrm{C}$. The two peaks $\mathrm{A}$ and $\mathrm{b}$ are reduced to a saddle after $100 \mathrm{~h}$ of aging (blue curve). Both vanish after about $250 \mathrm{~h}$ of aging (green curve). It can be concluded that earliest after $250 \mathrm{~h}$ and latest after $1,000 \mathrm{~h}$ aging at $190{ }^{\circ} \mathrm{C}$ all GPB zones have transformed to S-phase and only S-phase exists.

This evolution of GPB zones and S-phase precipitates agrees with former DSC analyses [29]. The authors found an endothermic effect between $160{ }^{\circ} \mathrm{C}$ and $240{ }^{\circ} \mathrm{C}$ which is attributed to the dissolution of $\mathrm{Cu}-\mathrm{Mg}$ co-clusters and GPB zones. Then, an exothermic peak follows between about $230{ }^{\circ} \mathrm{C}$ and $340{ }^{\circ} \mathrm{C}$ which corresponds to the formation of S-phase precipitates. Another endothermic effect GPB zones) as well as the following exothermic peak $\mathrm{b}$ (related to the S-phase precipitation) decreases in
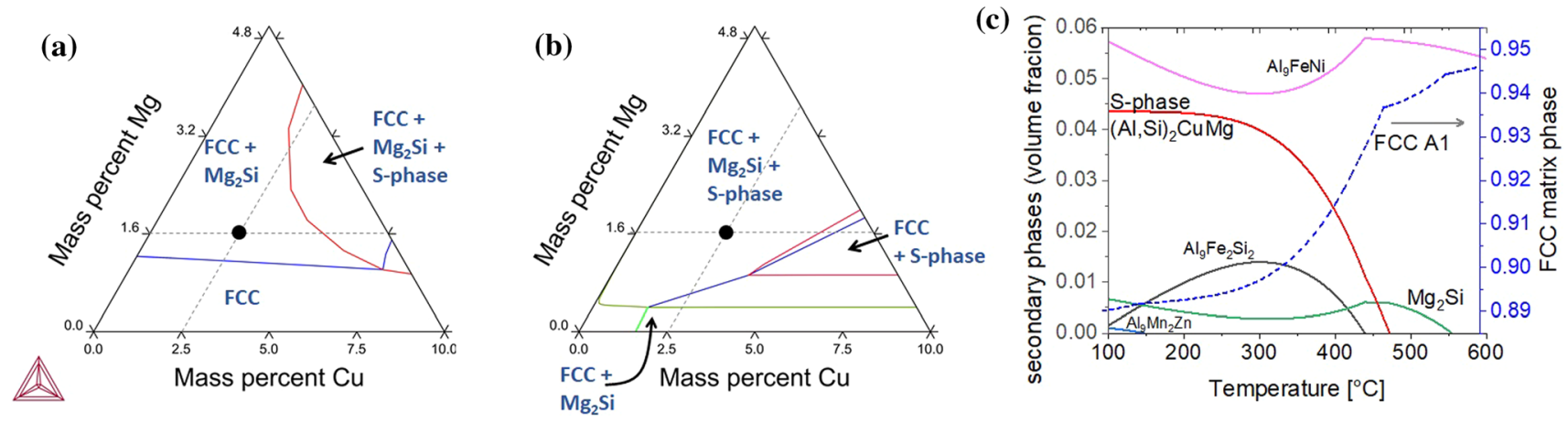

Figure 2 Section of quasi-ternary phase diagrams at a $530{ }^{\circ} \mathrm{C}$ and $\mathbf{b} 190{ }^{\circ} \mathrm{C}$. c Development of phase fractions as a function of temperature. 


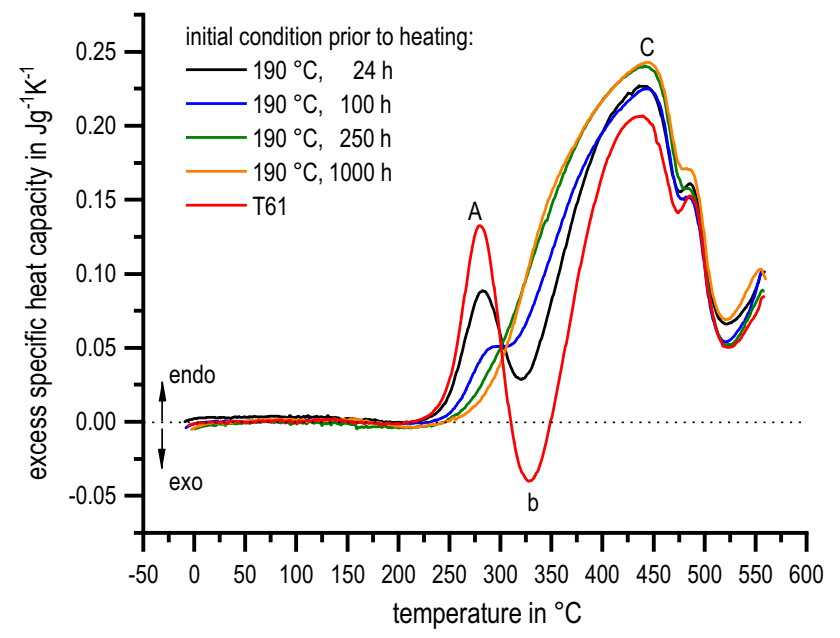

Figure 3 Average DSC curves of the samples in initial conditions T61 as well as aged at $190{ }^{\circ} \mathrm{C}$ for $24 \mathrm{~h}, 100 \mathrm{~h}, 250 \mathrm{~h}$ and $1,000 \mathrm{~h}$.

between $340{ }^{\circ} \mathrm{C}$ and $500{ }^{\circ} \mathrm{C}$ is connected to the dissolution of S-phase. The temperatures reported in [29] for the GPB zone dissolution and S phase formation are close to those found in our investigations. The slight differences can be explained by the faster heating rate used here (causing peak shifts to higher temperatures) and by the differences in the chemical compositions of the alloys considered.

\section{TEM measurements}

Dark-field transmission electron microscopy (DFTEM) was performed to systematically investigate the $\mathrm{S}-\mathrm{Al}_{2} \mathrm{CuMg}$ precipitate radii evolution. DFTEM allows selective imaging of the S-phase precipitates and GPB zones. The S-phase precipitates form as rods along the $<001>_{\alpha}$ direction of the $\alpha$-Al matrix. The GPB zones as predecessors of the S-phase are also oriented along this direction. Therefore, the samples were oriented in the $[001]_{\alpha}$ direction for the DFTEM investigations. Figure 4 shows a selected area diffraction pattern of the investigated Sample 1 (T61) with clearly visible reflections of the oriented Al-matrix exemplary for all samples. The rod-shaped precipitates cause the streaks in between the matrix reflections [35]. An aperture was used to select the streaks for dark-field imaging as indicated by the circle. The insertion of the aperture also excludes contrast contributions of the primary phases present in the samples $\left(\mathrm{Al}_{9} \mathrm{FeNi}, \mathrm{Mg}_{2} \mathrm{Si}\right)$.

Representative dark-field images of the $\mathrm{S}-\mathrm{Al}_{2} \mathrm{CuMg}$ precipitates are shown in Fig. 5a-g. The contrast of all presented DFTEM images was (linearly) enhanced for better visibility. The spots with bright contrast correspond to S-phase precipitates and GPB zones oriented along the $[001]_{\alpha}$ direction and penetrate the image plane. The elongated lath-shaped contrasts are caused by rods oriented orthogonal to the incident electron beam. The rods are imaged along the $[001]_{\alpha \prime}$ $[010]_{\alpha}$ and $[100]_{\alpha}$ directions of the Al matrix. Rods aligned along the $[001]_{\alpha}$ direction (i.e., with their rod axis orthogonal to the image plane) produce more contrast in comparison with the rods orientated orthogonal to the incident beam direction $[001]_{\alpha}$ (i.e., with their rod axis parallel to the image plane), since the electron beam passes a larger number of piled-up atomic planes for the former variant. The latter are only passed by the electron beam across their diameter and thus produce less contrast. The bright contrast spots in Fig. 5a correspond to the precipitates of the initial T61 state. According to the DSC results, GPB zones and S-phase exist. Coarsening of the initially smaller particles elapses during isothermal heat treatments at $190{ }^{\circ} \mathrm{C}$ for $250 \mathrm{~h}, 1,000 \mathrm{~h}, 2,500 \mathrm{~h}$, $5,000 \mathrm{~h}, 8,760 \mathrm{~h}$, and 25,000 h. The resulting larger bright contrasts can be seen in Fig. 5b-g). According to the DSC results, from $1000 \mathrm{~h}$ on, only S-phase exists. All precipitates imaged by DFTEM were in the following analysis considered as cylindrical rods with radius, $r$, and length, $l$. It was not possible to quantify the length of the precipitates due to the low contrast of the rods parallel to the image plane.

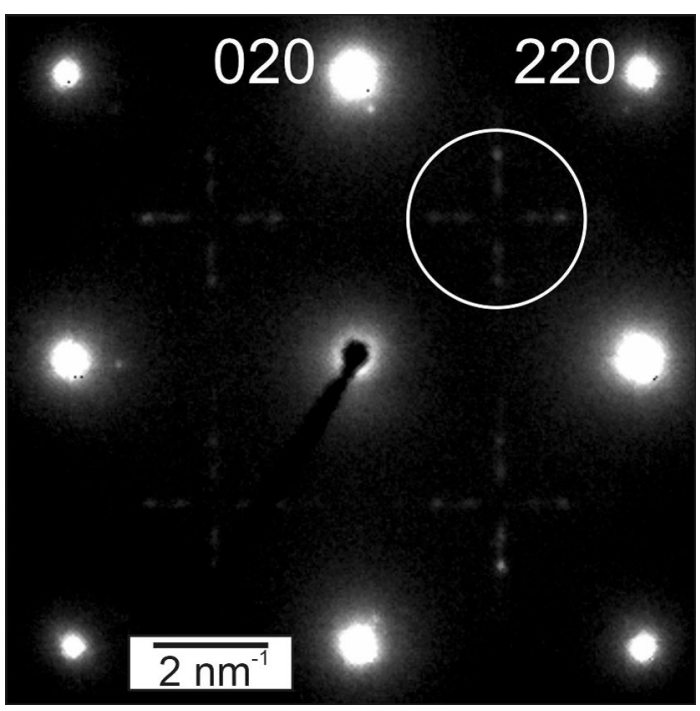

Figure 4 Diffraction pattern for the investigated area of Sample 1 (T61 state); the image was rotated. 

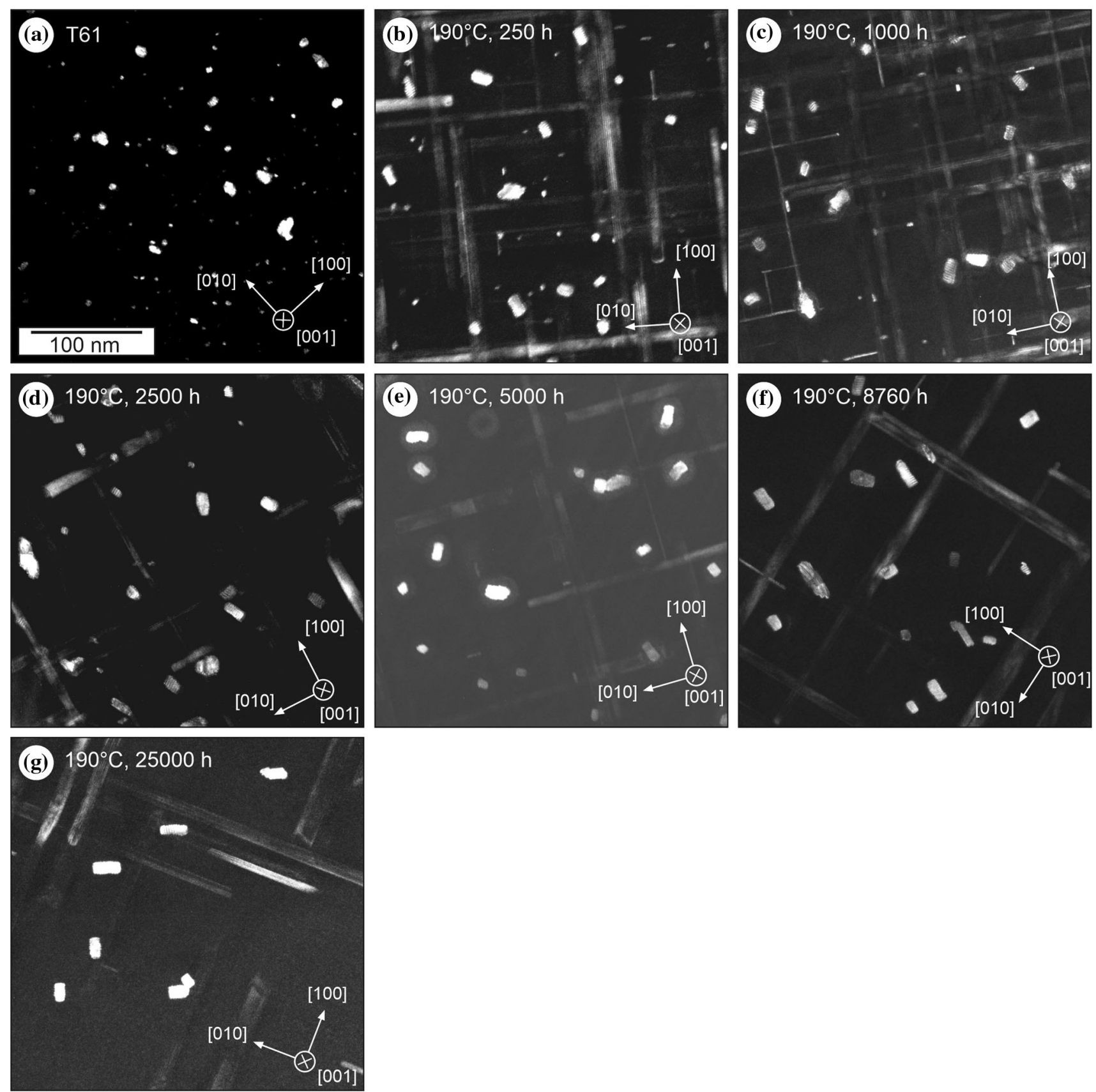

Figure 5 Dark-field images of the $\mathrm{S}-\mathrm{Al}_{2} \mathrm{CuMg}$ precipitates oriented along the [001] zone axis of the Al-matrix for a Sample 1 (T61), b Sample 4 (250 h), c Sample 5 (1,000 h), d Sample 6 (2,500 h), e Sample 7 (5,000 h), f Sample 8 (8,760 h), g Sample 9 (25,000 h).

Therefore, the quantitative analysis focused on the precipitate radius.

Radii distributions were obtained from the images using a standard procedure described in a previous publication [28]. The $\mathrm{S}-\mathrm{Al}_{2} \mathrm{CuMg}$ precipitates from multiple images of each sample were evaluated and then used to generate cumulative radii distributions functions normalized to the total number of precipitates for each sample. A log-normal distribution [36]

$$
n(r)=\frac{1}{2 \sqrt{2 \pi} r \sigma_{\text {geo }}} \exp \left(\frac{\left(\ln \left(\frac{r}{r_{m}}\right)\right)^{2}}{2 \sigma_{\text {geo }}}\right)
$$

with the particle radius, $r$, the median particle radius, $r_{\mathrm{m}}$ and the geometric standard deviation, 

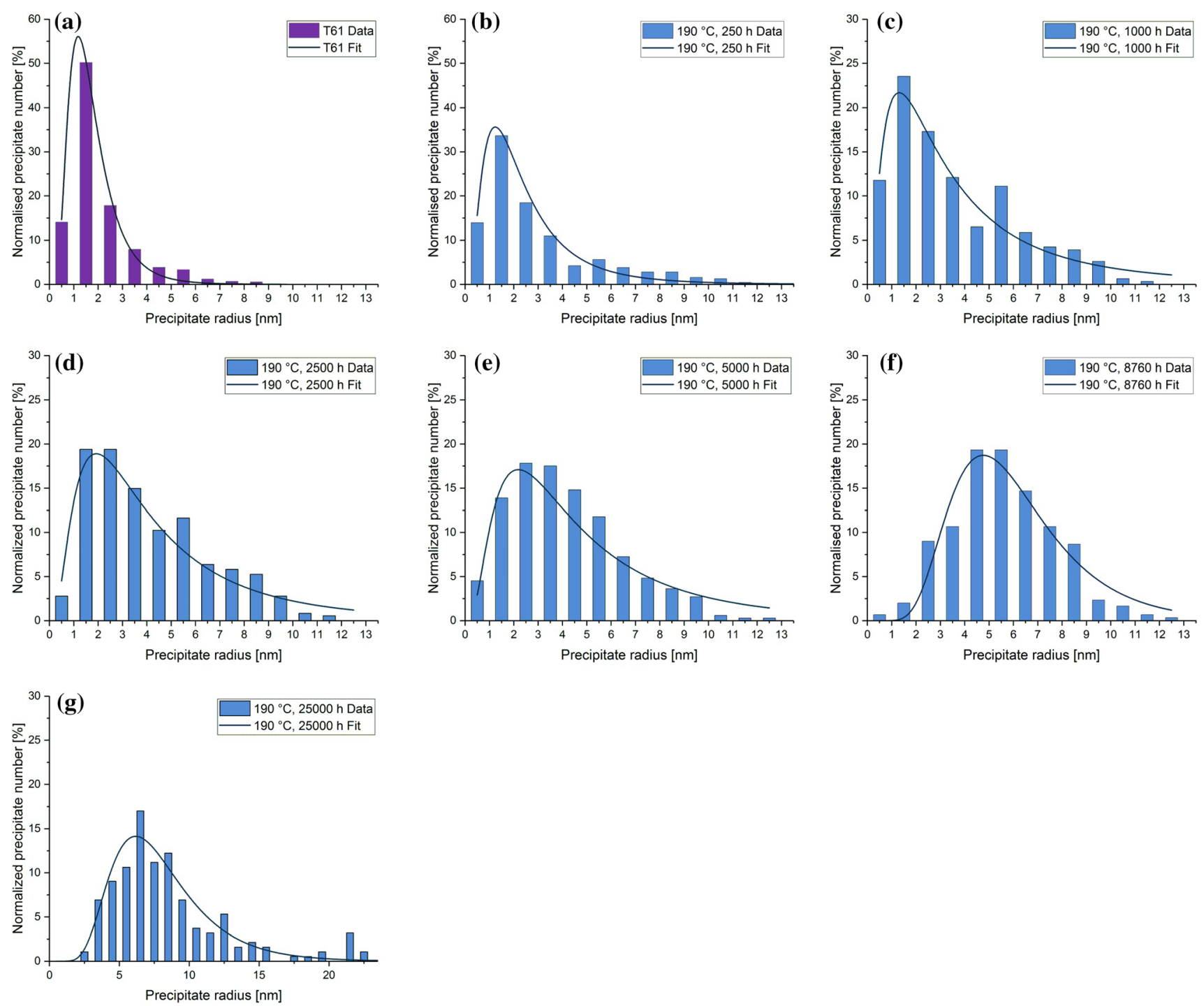

Figure 6 Fits of radii distributions including data of a Sample 1 (T61), b Sample 4 (250 h), c Sample 5 (1,000 h), d Sample 6 (2,500 h), e Sample 7 (5,000 h), f Sample 8 (8,760 h), g Sample $9(25,000$ h).

$\sigma_{\text {geo, }}$ was used as fitting function for the measured radii distributions. The comparison of the experimental data and the fitted functions according to eqn. (3) are shown in Fig. 6a-g. The bars correspond to the experimentally determined number of particles in the investigated samples and are normalized to the total number of precipitates found for the respective state. The number of particles for each state was at least 300 from at least two different samples with at least ten evaluated images except for Sample 9. Due to the long aging time of $25,000 \mathrm{~h}$, the precipitate density is lower and only 188 precipitates were evaluated. The fitted log-normal distributions are plotted as a line in the graphs and show good agreement with the experimental data.
The radii distributions in Fig. 6a-g indicate that during aging with increasing duration, the initially narrow distribution (Sample 1) broadens (Samples 2-7) and the distribution maximum moves to higher radii. Note the different scales of the y-axis in Fig. 6 a and Fig. $6 \mathrm{~b}$ and of the $\mathrm{x}$-axis in Fig. $6 \mathrm{~g}$. Parameters $r_{\mathrm{m}}$ and $\sigma_{\text {geo }}$ were determined from the raw data for all samples and are given in Table 2 . The resulting average radius, $r_{a}$, can then be calculated:

$r_{a}=r_{m} \exp \left(\frac{\sigma_{g e o}^{2}}{2}\right)$

The development of the average particle radii, $r_{\mathrm{a}}$, calculated using eqn. (4) vs. time is shown in Fig. 7. 


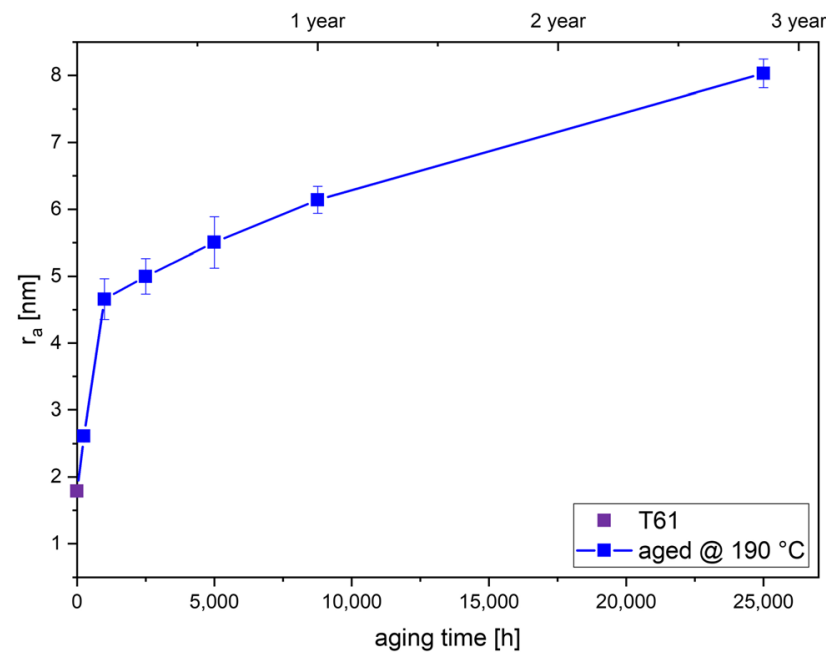

Figure 7 Average precipitate radius, $r_{a}$, vs. aging time, $t$, of Samples 1,4 to 9 . The line is only a guide to the eye for convenience.

The average radius increases which indicates that coarsening of the precipitates took place.

It is striking that there is a pronounced change in slope at 1,000 h: The initial strong increase decelerates, and the coarsening slows down considerably. This point coincides with finishing GPB zone dissolution according to DSC results. Radius $r_{\mathrm{a}}$ increases by $2.86 \mathrm{~nm}$ from initially $1.79 \mathrm{~nm}$ (T61 state) to $4.65 \mathrm{~nm}$ during the first $1,000 \mathrm{~h}$ of aging (factor $\sim 2.6$ ). The following increase of $3.38 \mathrm{~nm}$ from $4.56 \mathrm{~nm}$ (after 1,000 h) to $8.03 \mathrm{~nm}$ (after 25,000 h) takes $24,000 \mathrm{~h}$ which is considerably longer. The error bars in the graph include the statistical error and the systematic error of the size measurement in the electron microscopical images.

\section{Discussion}

The results described for the development of hardness, DSC heating curves and precipitate radii clearly show the expected degradation of the strengthening phases in the alloy during aging. The GPB zones transform to S-phase and further coarsen depending on the time of the heat treatment (Fig. 5). The coarsening changes the precipitates distribution and increases the effective interparticle spacing $\lambda$ which then according to eqn. (2) leads to degradation in material strength and hardness (Fig. 1). This qualitative result corresponds well to previous studies performed at higher temperatures $\left(205^{\circ} \mathrm{C}-300{ }^{\circ} \mathrm{C}\right)$ by
Ceschini et al. albeit the temperature in our study was lower $\left(190^{\circ} \mathrm{C}\right)$ [25]. The investigations of Nový et al. at $270{ }^{\circ} \mathrm{C}$ also exhibit comparable qualitative degradation phenomena [26, 27]. However, the coarsening process cannot be directly compared, since these studies examined mainly aging under load conditions (creep). In contrast, our present study focuses on isothermal aging without external loads.

The results reported here complement and improve upon previous results presented by Rockenhäuser et al. regarding a quantitative description of S-phase coarsening in alloy 2618A [28]. The previous study was able to quantify and explain the coarsening under external load conditions (creep) [28]. In this case, it was possible to explain the ripening process for stressed samples considering a model which included diffusion along dislocations. The quantitative description of the S-phase ripening process without external load remained, however, open. Several factors limited the transferability of the model. Firstly, the TEM data were restricted to $0 \mathrm{~h}$ (T61), $250 \mathrm{~h}, 2,500 \mathrm{~h}$, and $5,000 \mathrm{~h}$ of aging at $190{ }^{\circ} \mathrm{C}$, which might be a time span too small to fully understand the process. In addition, the dissolution process of the GPB zones present in the T61 state seems to be accelerated and completed faster under load. This could be governed by pipe diffusion and/or stressdriven fluxes, rather than normal diffusion, which then may not be captured using a simple coarsening model

The first problem was overcome by investigating additional samples by TEM $(1,000 \mathrm{~h}, 8,760 \mathrm{~h}$, and $25,000 \mathrm{~h}$ ). The resulting data of the average radii (Fig. 7) were used to study the Ostwald ripening model introduced (eqn. 1), for the isothermal aging process. The fit of $\left(r_{a}^{3}-r_{0}^{3}\right)$ vs. aging time is shown in Fig. 8a. (The upper $x$-axis shows the aging time in years and the lower one in hours.) Here, the average precipitate radius $r_{\mathrm{a}}=1.79 \mathrm{~nm}$ of the T61 state and $t_{0}$ $=0$ was used as initial mean radius $r_{0}$.

It is immediately apparent that the Ostwald ripening law (eqn. 1) does not describe the process for coarsening times all through $0 \mathrm{~h}$ to $25,000 \mathrm{~h}$, satisfactorily. The data points deviate strongly from the fitted graph, and the fit quality is poor (slope: $6.05 \cdot 10^{-6} \mathrm{~nm}^{3} \mathrm{~s}^{-1} \pm 8.3 \%$ ).

To assess the influence of GPB zones on the coarsening process, DSC measurements were performed. The measurements give insight on the 

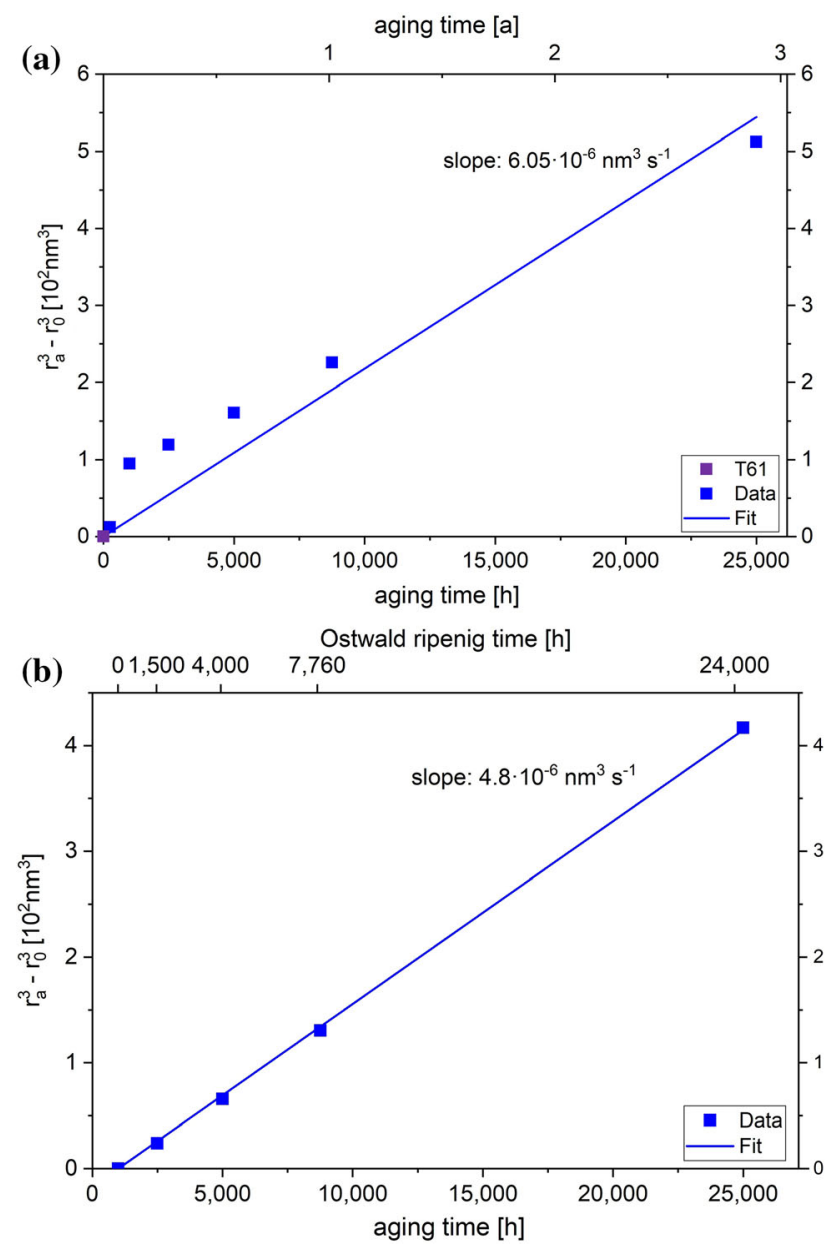

Figure 8 Ostwald ripening $\mathbf{a}$ from $0 \mathrm{~h}$ aging and $\mathbf{b}$ from $1,000 \mathrm{~h}$ aging onward.

presence of GPB zones during the early stages of the coarsening process. It is apparent from Fig. 3 that the curve for Sample 5 clearly shows no GPB zones left in the sample after $1,000 \mathrm{~h}$ of aging. Thus, for aging times $<1,000 \mathrm{~h}$ a dissolution of GPB zones and growth/ripening of S-phase may occur.

To address the question of why the kinetics of coarsening slow down after the GPB zones are dissolved, the data from Fig. 7 were replotted on logarithmic scales (Fig. 9). In addition, the expected slopes of $1 / 2$ for pure growth (red dashed line) and $1 / 3$ for pure coarsening (blue dash-dotted line) are overlaid in this graph. Zener [37] has shown that the development of the radius of cylindrical precipitates is characterized by a diffusion-controlled growth with $t^{1 / 2}$. On the other hand, the Ostwald ripening/coarsening, which is dominated by competitive evolution of the precipitates of different sizes, is shown to follow $t^{1 / 3}[20,21]$. A comparison with the experimental

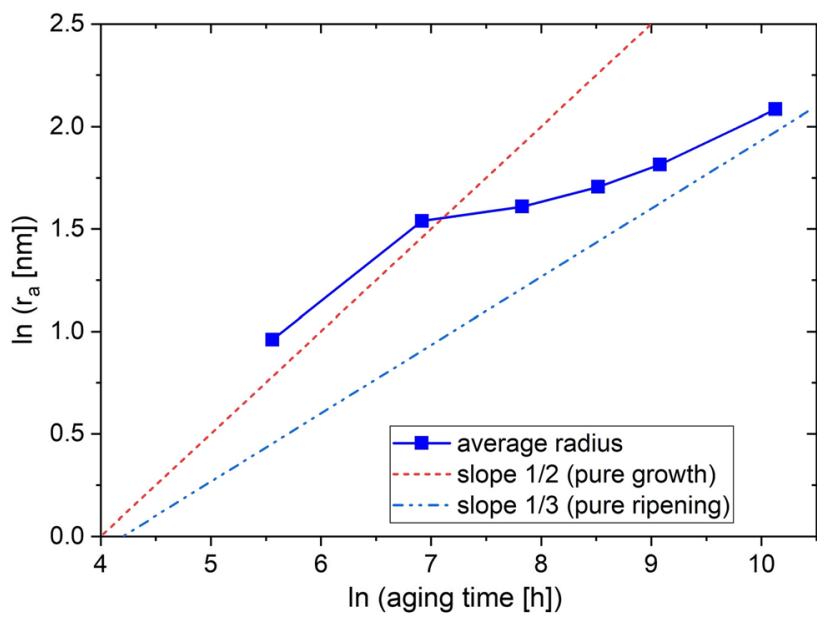

Figure 9 Logarithm of data from Fig. 7 and expected slopes for pure growth and coarsening.

data for the average radii in Fig. 9 shows that up to $1,000 \mathrm{~h}$ the slope is closer to $1 / 2$, changes for times $>1,000 \mathrm{~h}$ and approaches the straight line for $1 / 3$ after very long times. This indicates that the processes for times up to $1,000 \mathrm{~h}$ are rather still characterized by the growth kinetics and only after 1,000 $\mathrm{h}$ the coarsening kinetics start to prevail. The GPB zones probably do not reach the coarsening stage, but dissolve earlier in favor of the S-phase, which is consistent with the DSC measurements as well.

Considering a start of the Ostwald ripening process at $t_{0}=1,000 \mathrm{~h}$ leads to a reasonable result, which is presented in Fig. $8 \mathrm{~b}$. The $\mathrm{x}$-axis at the bottom shows the total coarsening time (as in Fig. 8a). Here, the average precipitate radius $r_{\mathrm{a}}=4.65 \mathrm{~nm}$ of Sample 5 (aging for 1,000 h) was used as initial mean radius $r_{0}$. Assuming a start of the ripening process at $t_{0}=$ $1,000 \mathrm{~h}$ allows to fit a model according to eqn. (1) to the data with a convincing result. The fit leads to a slope of $4.8 \cdot 10^{-6} \mathrm{~nm}^{3} \mathrm{~s}^{-1} \pm 0.7 \%$ with little deviation of the data from the fit:

$r_{a}^{3}=4.8 \cdot 10^{-6} t+83.26\left[\mathrm{~nm}^{3}\right]$

The x-axis at the top of Fig. $8 \mathrm{~b}$ shows the "Ostwald ripening time" of samples with aging of $1,000 \mathrm{~h}$ or more (Sample 5 to 9), where the coarsening time of $1,000 \mathrm{~h}$ (Sample 5) corresponds to the beginning of the Ostwald ripening. This means that the ripening process can be understood in a quantitative manner for long-term aging after an initial co-ripening stage up to $1,000 \mathrm{~h}$ during which a dissolution of GPB zones and ripening of S-phase occur. 
The results thus provide a quantitative description of the coarsening process over a significantly long time of aging, applicable to the realistic operation conditions of alloy 2618A. These outputs can be directly combined with the lifetime prediction models for a safer design of engine components.

\section{Conclusions}

The isothermal load-free aging of the aluminum alloy $2618 \mathrm{~A}$ in the $\mathrm{T} 61$ condition was investigated at $190{ }^{\circ} \mathrm{C}$ for long durations. The coarsening of the $\mathrm{S}-\mathrm{Al}_{2} \mathrm{CuMg}$ phase and its precursor (GPB zones) was studied by transmission electron microscopy (TEM), and the radius of the rod-shaped precipitates was quantified. Classical Ostwald ripening models could not be applied for a quantitative description of the precipitate evolution under short-time aging or external load, as a previous work has shown [28]. Here, TEM analysis was complemented by thorough differential scanning calorimetry (DSC) measurements allowing a more in-depth investigation of very long aging process up to $25,000 \mathrm{~h}$. The prolonged aging study reveals the long-term stability of the aging model. The results show that:

- The average precipitate radius, $r_{\mathrm{a}}$ initially increases very quickly with a pronounced change in slope after $1,000 \mathrm{~h}$ aging. This is found to be due to the initial growth kinetics of the precipitates. The coarsening kinetics slow down considerably afterward.

- The DSC results clearly indicate the coexistence of GPB zones and S-phase for shorter aging times. It is likely that for aging times $<1,000 \mathrm{~h}$ GPB zones and S-phase coexist: GPB zones dissolve, and new S-phase is formed.

- An Ostwald ripening law according to eqn. 1 (plotting $\left(r_{\mathrm{a}}{ }^{3}-r_{0}{ }^{3}\right)$ vs. aging time) does not describe the process for coarsening times from 0 to $25,000 \mathrm{~h}$ satisfactorily. It is shown that a growth to ripening mechanism change occurs around $1,000 \mathrm{~h}$.

- Therefore, the approach was chosen to consider the ripening only after the complete dissolution of the GPB zones, i.e., for 1,000 $\mathrm{h}$ and longer, where only the S-phase coarsens. For this purpose, $r_{0}$ was chosen to be $r_{\mathrm{a}}\left(t_{0}=1,000 \mathrm{~h}\right)$. The model fit to the data provides a ripening according to eqn. (5) which quantitatively describes the evolution of precipitates between 1,000 and 25,000 h.

Our results enable a quantitative description of the precipitation evolution. Combining these results with the underlying metallurgical understanding of the coarsening process allows now a realistic assessment of the operating engine components made of 2618A. The current results can be directly combined with the lifetime prediction models of those components.

\section{Acknowledgements}

The authors express their thanks to the Research Association for Combustion Engines (FVV, Frankfurt) for the selection of this research Project as well as to the German Federal Ministry of Economic Affairs and Energy (BMWi) and the German Federation of Industrial Research Associations (AiF) for funding (IGF-No. 17734).

\section{Authors' contribution}

CRoc contributed to conceptualization, methodology, TEM examinations and evaluations, visualization, data curation, and writing-original draft. CRow performed DSC measurements, contributed to the design and discussion of DSC experiments and writing the manuscript. BM contributed to the design and discussion of DSC experiments and writing the manuscript. RDK performed Thermo-Calc calculations, contributed to kinetics assessments and writing the manuscript. OK contributed to the design and discussion of DSC experiments and writing the manuscript. BS helped with conceptualization, writing-review and editing, supervision, project administration, and funding acquisition.

\section{Funding}

Open Access funding enabled and organized by Projekt DEAL. 


\section{Data Availability}

The raw/processed data required to reproduce these findings cannot be shared at this time as the data also form part of an ongoing study.

\section{Compliance with ethical standards}

Conflict of interest The authors declare that they have no known competing financial interests or personal relationships that could have appeared to influence the work reported in this paper

Open Access This article is licensed under a Creative Commons Attribution 4.0 International License, which permits use, sharing, adaptation, distribution and reproduction in any medium or format, as long as you give appropriate credit to the original author(s) and the source, provide a link to the Creative Commons licence, and indicate if changes were made. The images or other third party material in this article are included in the article's Creative Commons licence, unless indicated otherwise in a credit line to the material. If material is not included in the article's Creative Commons licence and your intended use is not permitted by statutory regulation or exceeds the permitted use, you will need to obtain permission directly from the copyright holder. To view a copy of this licence, visit http://creativecommons.org/licen ses/by $/ 4.0 /$.

\section{References}

[1] Polmear IJ (2006) Light alloys, 4th edn. ButterworthHeinemann, Burlington, MA, USA

[2] Oguocha INA, Yannacopoulos S, Jin Y (1996) The structure of Al x FeNi phase in Al-Cu-Mg-Fe-Ni alloy (AA2618).

J Mater Sci 31:5615-5621. https://doi.org/10.1007/bf 01160806

[3] Bergsma SC, Li X, Kassner ME (1996) Effects of thermal processing and copper additions on the mechanical properties of aluminum alloy ingot AA 2618. J Mater Eng Perform 5:100-102. https://doi.org/10.1007/bf02647276

[4] Wang JH, Yi DQ (2006) Preparation and properties of alloy 2618 reinforced by submicron AlN particles. J Mater Eng Perform 15:596-600. https://doi.org/10.1361/ 105994906x136133

[5] Elgallad EM, Shen P, Zhang Z, Chen XG (2014) Effects of heat treatment on the microstructure and mechanical properties of AA2618 DC cast alloy. Mater Design 61:133-140. https://doi.org/10.1016/j.matdes.2014.04.045

[6] Shih HC, Ho NJ, Huang JC (1996) Precipitation behaviors in $\mathrm{Al}-\mathrm{Cu}-\mathrm{Mg}$ and 2024 aluminum alloys. Metall Mater Trans A 27(9):2479-2494

[7] Liu G, Zhang GJ, Ding XD, Sun J, Chen KH (2003) Modeling the strengthening response to aging process of heat-treatable aluminum alloys containing plate/disc- or rod/ needle-shaped precipitates. Mater Sci Eng A 344:113-124. h ttps://doi.org/10.1016/s0921-5093(02)00398-2

[8] Khan IN, Starink MJ, Yan JL (2008) A model for precipitation kinetics and strengthening in $\mathrm{Al}-\mathrm{Cu}-\mathrm{Mg}$ alloys. Mater Sci Eng A 472:66-74. https://doi.org/10.1016/j.msea.2007. 03.033

[9] Wang SC, Starink MJ, Gao N (2006) Precipitation hardening in Al-Cu-Mg alloys revisited. Scr Mater 54:287-291. http s://doi.org/10.1016/j.scriptamat.2005.09.010

[10] Parel TS, Wang SC, Starink MJ (2010) Hardening of an Al$\mathrm{Cu}-\mathrm{Mg}$ alloy containing Types I and II S phase precipitates. Mater Design 31:S2-S5. https://doi.org/10.1016/j.matdes.2 009.12.048

[11] Perlitz H, Westgren A (1943) The crystal structure of $\mathrm{Al}_{2} \mathrm{CuMg}$. Ark Kem Mineral Geol 16:1-5

[12] Heying B, Hoffmann RD, Pottgen R (2005) Structure refinement of the S-phase precipitate $\mathrm{MgCuAl}_{2}$. Z Naturforsch 60b:491-494

[13] Silcock JM (1961) The structural ageing characteristics of $\mathrm{Al}-\mathrm{Cu}-\mathrm{Mg}$ alloys with copper-magnesium weight ratios of 7-1 and 2.2-1. J I Met 89(6):203-210

[14] Hardy HK, Heal TJ (1954) Report on precipitation. Prog Met Phys 5:143-278. https://doi.org/10.1016/0502-8205(54)900 06-4

[15] Ringer SP, Hono K, Polmear IJ, Sakurai T (1996) Nucleation of precipitates in aged $\mathrm{Al}-\mathrm{Cu}-\mathrm{Mg}-(\mathrm{Ag})$ alloys with high $\mathrm{Cu}$ : $\mathrm{Mg}$ ratios. Acta Mater 44:1883-1898

[16] Ringer SP, Hono K, Sakurai T, Polmear IJ (1997) Cluster hardening in an aged Al-Cu-Mg alloy. Scr Mater 36:517-521

[17] Ringer SP, Sakurai T, Polmear IJ (1997) Origins of hardening in aged Al-Cu-Mg-(Ag) alloys. Acta Mater 45:3731-3744

[18] Styles MJ, Hutchinson CR, Chen Y, Deschamps A, Bastow TJ (2012) The coexistence of two $\mathrm{S}\left(\mathrm{Al}_{2} \mathrm{CuMg}\right)$ phases in Al-Cu-Mg alloys. Acta Mater 60:6940-6951. https://doi.or g/10.1016/j.actamat.2012.08.044

[19] Styles MJ, Marceau RKW, Bastow TJ, Brand HEA, Gibson MA, Hutchinson CR (2015) The competition between metastable and equilibrium $\mathrm{S}\left(\mathrm{Al}_{2} \mathrm{CuMg}\right)$ phase during the decomposition of AlCuMg alloys. Acta Mater 98:64-80. h ttps://doi.org/10.1016/j.actamat.2015.07.011 
[20] Lifshitz IM, Slyozov VV (1961) The kinetics of precipitation from supersaturated solid solution. J Phys Chem Solids $19: 35-50$

[21] Wagner C (1961) Theorie der Alterung von Niederschlägen durch Umlösen (Ostwald-Reifung), Zeitschrift für Elektrochemie, Berichte der Bunsengesellschaft für physikalische. Chemie 65:581-591. https://doi.org/10.1002/bbpc. 19610650704

[22] Speich GR, Oriani RA (1965) Rate of coarsening of copper precipitate in an alpha-iron matrix. Trans Metall Soc AIME 233:623-631

[23] Monzen R, Tada T, Sea T, Higashimine K (2004) Ostwald ripening of rod-shaped alpha-Fe particles in a $\mathrm{Cu}$ matrix. Mater Lett 58:2007-2011. https://doi.org/10.1016/j.matlet.2 003.12 .018

[24] Polmear I, StJohn D, Nie JF, Qian M (2017) Light alloys: metallurgy of the light metals. Butterworth-Heinemann, UK

[25] Ceschini L, Morri A, Morri A, Di Sabatino M (2015) Effect of thermal exposure on the residual hardness and tensile properties of the EN AW-2618A piston alloy. Mater Sci Eng A 639:288-297. https://doi.org/10.1016/j.msea.2015.04.080

[26] Nový F, Janeček M, Král R (2009) Microstructure changes in a 2618 aluminium alloy during ageing and creep. J Alloy Compd 487:146-151. https://doi.org/10.1016/j.jallcom.200 9.08.014

[27] Nový F, Janeček M, Král R, Hadzima B (2012) Microstructure evolution in a 2618 aluminium alloy during creep-fatigue tests. Int J Mater Res 103:688-693

[28] Rockenhäuser C, Schriever S, Hartrott Pv, Piesker B, Skrotzki B (2018) Comparison of long-term radii evolution of the S-phase in aluminum alloy during ageing and creep. Mater Sci Eng A 716:78-86. https://doi.org/10.1016/jmsea 201801033

[29] Wang SC, Starink MJ (2007) Two types of S phase precipitates in Al-Cu-Mg alloys. Acta Mater 55:933-941. https://d oi.org/10.1016/j.actamat.2006.09.015
[30] DIN EN 515:2017, Aluminium and aluminium alloys Wrought products - Temper designations, Beuth-Verlag

[31] DIN EN 573-3:2019, Aluminium and aluminium alloys Chemical composition and form of wrought products - Part 3: Chemical composition and form of products, BeuthVerlag

[32] EN ISO 6506-1:2014, Metallic materials - Brinell hardness test - Part 1: Test method, Beuth Verlag

[33] Unlu N (2008) Preparation of high quality Al TEM specimens via a double-jet electropolishing technique. Mater Charact 59:547-553. https://doi.org/10.1016/j.matchar.2007. 04.003

[34] Kemsies RH, Milkereit B, Wenner S, Holmestad R, Kessler O (2018) In situ DSC investigation into the kinetics and microstructure of dispersoid formation in $\mathrm{Al}-\mathrm{Mn}-\mathrm{Fe}-\mathrm{Si}(-\mathrm{Mg})$ alloys. Mater Design 146:96-107. https://doi.org/10.1016/j. matdes.2018.03.007

[35] Wang SC, Starink MJ (2005) Precipitates and intermetallic phases in precipitation hardening (Al-Cu-Mg-(Li) based alloys. Int Mater Rev 50:193-215. https://doi.org/10.1179/ $174328005 X 14357$

[36] Du Q, Holmedal B, Friis J, Marioara CD (2016) Precipitation of Non-spherical particles in aluminum alloys Part II: numerical simulation and experimental characterization during aging treatment of an Al-Mg-Si Alloy. Metall Mat Trans A 47:589-599. https://doi.org/10.1007/s11661-015-3 196-6

[37] Zener C (1949) Theory of growth of spherical precipitates from solid solution. J Appl Phys 20:950-953. https://doi.org/ $10.1063 / 1.1698258$

Publisher's Note Springer Nature remains neutral with regard to jurisdictional claims in published maps and institutional affiliations. 